\title{
Simmel e Goffman: uma comparação possível
}

\section{Simmel and Goffman: a possibility of comparison}

\section{I sabelle de Paiva Sanchis*}

Universidade Federal de Minas Gerais - UFMG, Belo Horizonte, Minas Gerais, Brasil

\begin{abstract}
RESUMO
Georg Simmel e Erving Goffman se situam no centro da problematização sobre a relação indivíduo/sociedade, tema fundamental na Psicologia Social, buscando categorias de mediação que ajudem a compreender a experiência dos sujeitos dentro da organização social. O objetivo deste trabalho é o de fazer um esforço de comparação entre duas dessas categorias - sociação, em Simmel, e frame em Goffman - inserindo-as na perspectiva mais ampla de cada um dos autores. Assim, são explicitadas também as concepções de indivíduo e de sociedade, em cada perspectiva, a fim de estabelecer um diálogo mais amplo e de vislumbrar a possibilidade de complementaridade entre as duas abordagens.
\end{abstract}

Palavras-chave: Simmel; Goffman; Sociação; Frame.

\begin{abstract}
Georg Simmel and Erving Goffman stand in the heart of the matter of individual/society relations question - basic subject in Social Psychology -, searching for categories of mediation that help to understand the experience of the individual of the social organization. The goal of this work is to make an effort towards the comparison between two of these categories sociation, in Simmel, and frame in Goffman - inserting them in the larger perspective of each of the authors. Thus, the conceptions of individual and of society are also set out, in each perspective, in order to establish a more substantial dialogue among them and to glimpse at the possibility of complementarity between the two approaches.
\end{abstract}

Keywords: Simmel; Goffman; Sociation; Frame.

\section{I ntrodução}

Simmel e Goffman viveram em épocas e lugares diferentes, e, apesar de tratarem do mesmo tema - o da relação indivíduo/sociedade -, buscando categorias de mediação que dessem conta de explicar a experiência do sujeito dentro da organização social, tinham preocupações um pouco distintas. Por exemplo, Simmel se deparava com mudanças bruscas na sociedade, e pensava nas conseqüências delas para as relações e para a própria experiência subjetiva dos indivíduos; enquanto Goffman se voltava mais para as situações concretas do cotidiano, para as regras que guiam as interações face- 
a-face. Assim, a sociação, categoria puramente relacional, se torna a base da teoria de Simmel, que escolhe analisar as formas sociais; e o frame, categoria que busca articular forma e conteúdo nas diversas situações de interação, ganha destaque na teoria de Goffman, quando pensamos na mediação entre os indivíduos e a sociedade. Pretende-se, nesse trabalho, ver a possibilidade de comparação entre os dois conceitos, tentando inseri-los na perspectiva mais ampla dos dois autores, e buscando, ao mesmo tempo, as concepções subjacentes de indivíduo e de sociedade presentes em cada perspectiva.

\section{Simmel e o conceito de sociação}

Simmel nasceu em Berlim em 1858 e faleceu em Estrasburgo em 1918. Começou a faculdade de história, mas logo passou para a filosofia, em que se formou com uma tese intitulada "A Natureza da matéria segundo a monadologia física de Kant". Por um lado, foi muito influenciado pelo neokantismo, marcante nessa época na Alemanha, e teve como grande preocupação o dualismo conteúdo e forma das relações sociais. Por outro, não abandona um certo horizonte filosófico, ainda que coloque a sociologia como um campo à parte, especificando a natureza de seu objeto e de seu método.

No final do séc. XIX, cresciam a indústria, o capitalismo e os centros urbanos. Em um espaço de tempo muito curto a Alemanha deixou de ser um país feudal para entrar na modernidade, e, com isso, Berlim, por exemplo, que era até então bem menor do que outras grandes capitais como Paris, Londres ou Nova Iorque, cresceu de forma extremamente rápida. Muitos intelectuais da época procuraram estudar temas presentes nessas transformações, como o capitalismo, a tecnologia, o status social, as classes sociais e, como Simmel, o dinheiro. Simmel se preocupa com o indivíduo frente ao novo mundo urbano e suas reações, e estuda formas específicas de interação tais como as que constituem a figura do estrangeiro, do metropolitano, do pobre, entre outras. Volta-se também para aspectos das experiências subjetivas delas decorrentes. Para ele, "os problemas mais profundos da vida moderna brotam da pretensão do indivíduo de preservar a autonomia e a peculiaridade de sua existência frente às superioridades da sociedade [...]" (SIMMEL, 2005, p. 577). O "tipo metropolitano" se via diante de muito mais liberdade, mas a um preço bastante alto. A diversidade de círculos sociais, a falta de vínculos que as relações tradicionais permitiam e o novo modo de divisão do trabalho propiciavam, nos centros urbanos, ao mesmo tempo uma excitação permanente (ou, nas palavras de Simmel, uma "intensificação da vida nervosa"), o sentimento de desamparo, a solidão e a alienação dentro de uma cadeia de produção. De fato, a 
formação da individualidade foi uma questão importante para Simmel. "Tanto mais rica é a participação do indivíduo na vida social, tanto maior o número de círculos sociais a que pertença, quanto mais forte é a sua independência, quanto mais nítida se destaca a sua personalidade" (MORAES FILHO, 1983, p. 23-24). Assim, Simmel pensa na sociedade em que vive, nos novos tipos de relações entre as pessoas e das pessoas com as coisas. O significado do dinheiro, por exemplo, está estreitamente ligado a essas mudanças, pois Simmel vê na economia do dinheiro um determinante das relações sociais na sociedade moderna (SIMMEL, 2005; STECHER, 1995). Ele trata da monetarização da vida moderna, como se o dinheiro, algo impessoal e universal, substituísse os vínculos de sangue e de parentesco no relacionamento entre as pessoas e delas com os grupos. A questão da individualidade se torna mais problemática, "pois o dinheiro indaga apenas por aquilo que é comum a todos [...]" (SIMMEL, 2005, p. 579), fazendo com que o espírito moderno se torne cada vez mais um "espírito contábil" (SIMMEL, 2005, p. 580).

A influência de Simmel foi grande para a Escola de Chicago, por sua sensibilidade cosmopolita, seu enfoque microssociológico (ainda que não tenha feito pesquisas empíricas) e por uma "interpretação da cultura que privilegia o jogo dinâmico entre estruturas simbólicas identitárias e forças de alteridade" (FERREIRA, 2000, p. 103). Ferreira traz um exemplo (2000, p. 116):

Simmel conclui que a ajuda ao pobre é explicada não pela força de algum tipo de abnegação ou altruísmo daqueles que são mais afortunados, mas para que este último grupo possa manter a estabilidade de sua identidade comunitária.

De fato, a concepção de sociedade de Simmel é diferente da de Durkheim, na mesma época, privilegiando o "devir", o acontecer, em lugar da ênfase nas pressões sociais. Aliás, por isso mesmo ele não fala de socialização, que pressupõe muito mais a formação do sujeito a partir das determinações sociais, mas sim de sociação, que seria a forma pura de interação entre os indivíduos. Sua sociologia, em certo sentido, é oposta à pretensão de Durkheim de determinar leis empíricas e universais para o mundo social. Ele se insere em uma visão pragmatista, para a qual não há verdade absoluta, "a verdade só é válida pelo que dela resultar de útil e prático, de eficaz para a espécie humana, isto é, representações verdadeiras nascem pela seleção" (MORAES FILHO, 1983, p. 17). Compartilhava com Dilthey a idéia de impossibilidade da história ser tratada como uma ciência natural. A psicologia seria o a priori da ciência histórica, pois "os dados da história, como realidade empírica, pertencem à experiência histórica do indivíduo" (MORAES FILHO, 1983, p. 17). A base psicológica está entre as mais fundamentais concepções de Simmel, 
junto com as noções de interação e de sociação, e com o dualismo forma-conteúdo.

Sua pergunta era: Como é possível a sociedade?

\begin{abstract}
Diferentemente da natureza, cujos fatos materiais concretos são ordenados pelas formas a priori (intuições puras e categorias) do espírito humano que as percebe [leitura a partir de Kant]; a unidade social realiza-se pela própria atividade dos componentes da sociedade, sem necessidade da ação mental sintetizadora de um sujeito que lhe é externo ou estranho (MORAES FILHO, 1983, p. 20).
\end{abstract}

Para Simmel, a sociedade não é, então, uma realidade em si. O indivíduo é o fundamento dos grupos. No entanto, seu interesse não estava nem na sociedade nem no indivíduo, mas sim na interação "produtora" entre os dois pólos. Na própria produção da sociedade pelos indivíduos e no seu inverso (sempre de forma concomitante), a permanente conformação dos indivíduos pela sociedade. Assim, mesmo a sociedade não sendo uma realidade independente e autônoma em relação aos indivíduos, também não era no indivíduo isolado que Simmel buscava fundamentá-la. Segundo Vandenberghe (2007), na verdade Simmel tinha uma idéia geral de que nas interações entre as pessoas estava o fundamento de todos os domínios da vida. Ele procurava "colocar-se num meio termo de equilíbrio, dando o indivíduo como o sujeito último da vida social, seu legítimo portador, mas sem desconhecer a existência das grandes formações sociais, como unidades próprias" (MORAES FILHO, 1983, p. 25). A ênfase é no indivíduo, mas no indivíduo em relação, em inter-relação.

A sociedade só é possível, então, como resultante das ações e reações dos indivíduos entre si. Resultante de processos intermentais. Ela não é estática nem substancializada, ela é, como diz Simmel, um "acontecer". E a sociologia, como ciência empírica, "deve ter por campo ou objeto a multiplicidade de interações". Nas palavras de Simmel (1983, p. 49), "para um olhar que penetrasse no fundo das coisas, todo fenômeno que parecesse constituir, acima dos indivíduos, alguma unidade nova e independente, se resolveria nas ações recíprocas permutadas pelos indivíduos".

A sociação, em contraposição à socialização, começa a existir quando "a coexistência isolada dos indivíduos adota formas determinadas de cooperação e de colaboração, que caem sob o conceito geral de interação". Ela "é, assim, a forma, realizada de diversas maneiras, na qual os indivíduos constituem uma unidade dentro da qual realizam seus interesses" (SIMMEL, 1983, p. 60). Essas maneiras diversas podem ser relações de aproximação/distanciamento, dominação/subordinação, conflito/convergência, etc. Mas os 
interesses, dos quais partem as sociações, parecem emergir de impulsos, ou instintos individuais.

A sociação pressupõe a interação de, no mínimo, duas pessoas, o que caracteriza uma díade, unidade básica da sociação. O ser humano se caracteriza exatamente por viver em interação, apesar de Simmel não explicar a origem dos "instintos" e interesses que o levam a isso. Assim sendo, a própria experiência individual pressupõe a vida social. Há, como coloca Nogueira (2006), uma anterioridade impositiva: as relações sociais são pré-existentes aos indivíduos. "Ao mesmo tempo, esses mesmos indivíduos é que dão sustentação a essas relações, pois, ao manterem entre si ações de reciprocidade, conformam a vida em sociedade" (p. 33) e dão concretude existencial a ela. É a própria experiência social que permite a dimensão da individualidade, "e faz com que palavras como liberdade e solidão" ( $p$. 76) ganhem sentido. As escolhas individuais só têm significado dentro de uma situação social. Por exemplo, o celibato é uma recusa individual à formação de determinada díade. Mas esse ato "permanece [...] vinculado a uma forma social [...] pressuposta" (NOGUEIRA, 2006, p. 76), que, no caso, é o matrimônio.

O processo fundamental de constituição da sociedade é então a sociação, formada pelos impulsos dos indivíduos, ou por motivos, interesses e objetivos; e pelas formas que essas motivações assumem. Daí a importância de se distinguir forma e conteúdo. O domínio da sociologia, para Simmel, está nas "formas que tomam os grupos de homens, unidos para viver uns ao lado dos outros, ou uns para os outros, ou então uns com os outros" (SIMMEL, 1983, p. 47). $\mathrm{E}$ as razões econômicas, religiosas, políticas, etc, pelas quais as sociações começam a existir, cabem a outras ciências. Ele distingue sociologia formal de sociologia geral. Ou seja, a sociologia formal deve estudar apenas as formas puras, desvinculadas de seus conteúdos, ao passo que a sociologia geral seria um subproduto da sociologia pura, e se ocuparia dos conteúdos particulares, dos "processos qualitativos" (ou conteúdos) que assumem as diversas formas. Segundo Cohn (1998), Simmel procurava "captar no momento mesmo da sua emergência os processos de sociação, aqueles em que os fluxos da experiência vivida ganham forma e persistem para além dos conteúdos íntimos originais". Simmel (1894) considerava um progresso da história e das ciências a tendência de procurar, nos acontecimentos individuais, pelos processos históricos e sociais. No entanto isso não delimita o campo da sociologia, não diz da sua especificidade, que seria a de tratar apenas do que é precisamente social, ou seja, das formas de sociação enquanto tal, e não dos interesses e objetos particulares que acontecem na e pela sociação (SIMMEL, 1894, p. 499). É preciso, então, separar o que acontece no interior da sociedade daquilo que acontece de fato pela sociedade. 
Existem várias condições formais de sociação, como a quantidade de indivíduos, o processo de dominação/subordinação, o conflito (com sua forma indireta da competição), etc. Deve-se então encontrar sociações que têm fins ou interesses muito diferentes, e ver o que elas têm em comum. As relações de dominação/subordinação, por exemplo, são relações formais dos indivíduos, e podem ser encontradas tanto num Estado, quanto numa comunidade religiosa ou artística, etc. (SIMMEL, 1983, p. 62). O fenômeno da formação dos partidos também pode acontecer tanto no mundo artístico como nos meios políticos. No entanto, a diferenciação entre forma e conteúdo é, na verdade, apenas um modo de abstração para que se compreendam os problemas sociológicos, pois em qualquer fenômeno social eles constituem uma realidade unitária; em qualquer experiência concreta, forma e conteúdo são indissociáveis, já que, necessariamente, os indivíduos interagem a partir de conteúdos (motivações, interesses, objetivos). Como analogia, Simmel (1894, p. 500) toma o exemplo da geometria, que "considera apenas a forma espacial do corpo, a qual, no entanto, não existe por si só, mas sempre em e com uma matéria, a qual [por sua vez] é objeto de outras ciências"1. Não há, também, uma distinção valorativa, apenas operacional (TAVARES, 2001). Na impossibilidade de apreender a multiplicidade e a complexidade das experiências da vida social, a sociologia formal deve, segundo Simmel, procurar pelas formas que assumem essas experiências, independente de seu conteúdo. Simmel (1894; 1983) busca nas formas sociais modelos de interação humana, mas esses modelos "não incorporam uma dimensão ontológica, presente, por exemplo, no conceito de lei social [...], são antes cristalizações da interação humana, sendo construídos a partir do referencial do pesquisador" (TAVARES, 2001, p. 80).

Ainda em relação à forma, Simmel ${ }^{2}$ (apud FERREIRA, 2000, p. 107) diz da sociedade moderna:

\begin{abstract}
A ponte entre o passado e o futuro das formas culturais parece ter sido demolida, nós olhamos sob nossos pés para dentro de um abismo de vida não formada. Mas talvez essa ausência de forma seja em si a forma mais apropriada da vida contemporânea.
\end{abstract}

Dessa maneira, as formas sociais não são estanques, mas estão em permanente processo de construção.

Quanto às relações formais dos indivíduos, não há sociação, e consequentemente sociedade, nos casos em que a importância de uma parte da relação é baixa o suficiente para que não exerça influência nenhuma sobre a outra parte. Simmel (1983) diz que quando a diferença de posições estratégicas entre patrões e trabalhadores atinge um nível muito alto, o contrato de trabalho 
deixa de ser de fato um contrato. Mas afirma que na relação de superordenação (ou dominação) e subordinação, exceto em raros casos (onde há violência física), há a liberdade da parte subordinada, que pode se submeter ao outro pelo desejo de "escapar de uma punição" ou de outras conseqüências. Isso significa que também estes casos constituem formas societárias, baseadas também em interações, ou ações recíprocas.

O conflito não só deve ser considerado uma forma de sociação, como também deve ser visto como algo positivo, que resolve tensões entre contrastes, e não que apenas cria divergências. Eles fazem parte da constituição da sociedade, de sua estruturação, não são somente elementos desagregadores. Há sempre, em qualquer relação social, uma tensão entre elementos convergentes e dissociativos. Para Simmel (1904), toda unidade contém, em sua história, além dos elementos propriamente unificadores, fatores que em um primeiro momento se colocavam em oposição à unificação. Ou seja, as formas sociais são compostas por relações de conflito em cooperação com forças unificadoras. Como exemplo, Simmel (1983) trata da vida urbana, em que "a extensão da antipatia (tida aqui como um modo de conflito), o ritmo de sua aparição e desaparição, as formas pelas quais é satisfeita, tudo isso, a par de elementos mais literalmente unificadores, produzem a forma de vida metropolitana insolúvel; e aquilo que à primeira vista parece desassociação, é na verdade uma de suas formas elementares de socialização" (p. 128).

Além disso, o conflito é um dos elementos que explicam a transformação, a produção da vida social, para além de sua reprodução: "[as] tensões presentes em todas as esferas (individual, grupal, social), bem como entre as esferas, encontram-se no âmago do jogo social, propiciando a decadência de formas de interação já cristalizadas e a ascensão de novas formas" (TAVARES, 2001, p. 85). Assim, o conflito é visto como estruturante das interações sociais, sendo um dos fatores a partir dos quais as relações concretas se constituem (SIMMEL, 1904).

Ainda pensando na dualidade forma/conteúdo, os conteúdos podem se tornar autônomos em relação às suas formas. Por exemplo, o conhecimento do comportamento das coisas é de utilidade para a promoção e manutenção da vida, mas a ciência se tornou um valor em si mesmo, ela "escolhe seus objetos de forma completamente autônoma, modela-os de acordo com suas próprias necessidades e não se interessa por mais nada além da sua própria perfeição" (SIMMEL, 1983, p. 167). Fazendo o raciocínio inverso, a forma pode também se tornar autônoma em relação aos conteúdos que originalmente a constituíram. Simmel nomeia esse fenômeno de sociabilidade, que é considerada por ele como a forma "Iúdica" de sociação, por carregar como valor o próprio processo de sociação, 
liberado de qualquer laço ou conteúdo. Simmel (1983, p. 178) traz exemplos históricos de sua concepção de sociabilidade. Um deles:

\begin{abstract}
Nos primórdios da Idade Média alemã, existiam irmandades de cavaleiros. Consistiam elas de famílias nobres que mantinham relações amistosas entre si. Os propósitos originalmente religiosos e práticos desses grupos parecem ter-se perdido bem cedo. No século XIV, só restavam os interesses e as formas de comportamento cavaleirescos como características de conteúdo, mas logo depois mesmo estes desapareceram, e nada ficou além de associações puramente aristocráticas. [...]. Uma vez que todo o seu conteúdo se perdeu, restou somente um resíduo que só podia consistir na forma e nas formas de comportamento recíproco.
\end{abstract}

Mais uma vez podemos ver que o fundamento último da sociedade se encontra nos indivíduos, pois nas palavras de Simmel (1983, p. 166):

a sociação é a forma (realizada de incontáveis maneiras diferentes) pela qual os indivíduos se agrupam em unidades que satisfazem seus interesses. Esses interesses, quer sejam sensuais ou ideais, temporários ou duradouros, conscientes ou inconscientes, causais ou teleológicos, formam a base das sociedades humanas.

Nesse sentido, os interesses não seriam constituídos, eles também, por processos sociais; ao contrário, estariam no próprio fundamento destes últimos, fazendo-nos pensar em instintos ou necessidades inerentes/inatas ao ser humano. Moraes Filho (1983, p. 29), criticando o apelo que Simmel faz aos instintos humanos para explicar o processo de sociação, traz um exemplo de "produção" de um instinto, tirado de Sumner e Keller ${ }^{3}$ :

Quando um escocês passa na escala de uma classe inferior para a classe média, os sapatos se tornam para ele uma necessidade. Não os usa para conservar os pés, mas para conservar a sua situação social [...]. Algum dia, um filósofo emitirá a opinião que os sapatos foram inventados por inata pudícia de mostrar os pés e teremos assim descoberto um novo instinto.

No entanto, apesar disso, Simmel (1983, p. 85) não reduz a sociedade aos instintos individuais e fala da produção dos fenômenos através da própria vida social, com um duplo sentido.

Primeiramente, pela ação recíproca e justaposta dos indivíduos, ação que produz dentro de cada um o que, a partir dele, não se explica; em segundo lugar, pela sucessão das gerações cujas heranças e tradições se fundem solidamente com as aquisições peculiares do indivíduo, 
fazendo com que o homem social, ao contrário de qualquer vida subhumana, não seja apenas um descendente, mas propriamente um herdeiro.

\section{Goffman e o conceito de frame}

Goffman (Alberta-Canadá, 1922/Pensilvânia, 1982) formou-se primeiramente em química em 1934, e foi trabalhar no National Film Board of Canadá, que produzia filmes documentários - mostrando desde cedo o gosto pela observação das interações concretas entre as pessoas. Em 1944 começou a estudar sociologia em Toronto, tendo ido depois para a universidade de Chicago. Lá foi aluno de Blumer, que tinha sido muito influenciado por Simmel, como, aliás, os pesquisadores da corrente microssociológica em geral. Fazendo parte da segunda geração da Escola de Chicago, Goffman dava muita importância à pesquisa empírica. Passou, por exemplo, dezoito meses estudando uma comunidade em uma das ilhas Shetland, na Escócia, que foi o objeto de sua tese de doutorado, defendida em 1953. Em 1961 publica Manicômios, Prisões e Conventos, depois de passar dois anos vivendo em um hospital psiquiátrico.

Goffman passa por diversos temas ao longo de sua obra. Tomando como metáfora o teatro, estuda, entre outros aspectos, os papéis sociais desempenhados pelas pessoas, que se referem à imagem que elas têm de si mesmas e que querem transmitir ao público. Na vida, como no teatro, os atores têm a tarefa de dar a esses papéis um caráter de verossimilhança, sendo o objetivo último colar o papel à realidade. Tratar as situações como cenas permite também ver uma das idéias que sempre o acompanharam: as interações são construídas através da produção de um "consenso operacional", evitando que o conflito - sempre presente - se manifeste, permitindo - fluxo da "representação". Goffman se interessa também pela condição social dos doentes mentais, e pela constituição social da diferença entre o normal e o patológico. Trata das semelhanças estruturais entre os rituais e as experiências cotidianas, e procura entender a maneira como as pessoas se comportam diante do outro. Fazendo uma alusão ao cinema, introduz o conceito de frame, traduzido por quadro ou esquema (MALUFE, 1992; NUNES, 1993), com o intuito de dar conta da relação entre a organização social e a experiência individual.

A diversidade de temas, que foi alvo de várias críticas (como, aliás, também aconteceu com Simmel), deve ser entendida através de algumas idéias que perpassam sua obra. Goffman teve como interesse principal o domínio das interações face-a-face, e reivindicava a autonomia desse campo, a legitimidade das interações cotidianas como autêntico objeto sociológico (GOFFMAN, 1991; 
JOSEPH, 2000; TRAJANO FILHO, 2008). Esse domínio, segundo ele, é regido por suas próprias regras. Não pode ser explicado nem em termos de forças macrossociológicas (por exemplo, noções como classe, aparelhos de poder) nem em termos psicológicos, como desejos ou motivações individuais. Com isso, ele busca a "estrutura da experiência individual da vida social" (GOFFMAN, 1991, p. 22), a "ordem das interações" (GOFFMAN, 1983). Tanto que, no discurso presidencial que ele deveria ter lido em 1982 no encontro da Associação Americana de Sociologia, ele resume, assim, suas intenções:

\begin{abstract}
A minha preocupação ao longo dos anos foi promover a aceitação deste domínio do face-a-face como um domínio analiticamente viável - um domínio que poderia ser intitulado, por falta de um nome mais feliz, de ordem da interação - um domínio cujo método de estudo preferido é a micro-análise (GOFFMAN, 1983, p. 2, tradução da autora ${ }^{4}$ ).
\end{abstract}

Uma ordem estrutural em que as estruturas só existem enquanto colocadas em prática a cada momento pelos atores, sendo que os próprios atores só podem colocá-las em prática a partir das próprias estruturas que guiam suas ações. Nesse contexto, a noção de situação ganha especial valor, pois é nela e a partir dela que esse processo ocorre.

Em Frame Analysis, Goffman (1991, p. 16) parte da pergunta: "o que está acontecendo aqui?". Essa questão supõe, antes de tudo, que exista uma situação, marcada no tempo, no espaço e nas suas características, que possa ser definida como real por todos os participantes. Apesar de reconhecer que as situações são vividas através de pontos de vista distintos, ele se propõe a identificar os quadros fundamentais que, em nossa sociedade, permitem compreender os acontecimentos. Seguindo o caminho de James, Goffman não se questiona sobre a natureza do real, mas pergunta com ele: "em quais circunstâncias pensamos que as coisas são reais"? (JAMES, apud GOFFMAN, 1991, p. 10). Se James, e também Schutz, colocavam o mundo da vida ordinária em um lugar privilegiado quanto à percepção de realidade, Goffman busca mostrar que existe uma semelhança estrutural entre a vida cotidiana e os outros múltiplos mundos dos quais os indivíduos participam: "algo que, em algumas circunstâncias, pode se apresentar como sendo a própria realidade, pode de fato não passar de uma brincadeira, um sonho, um acidente, um mal-entendido, uma ilusão, uma representação teatral, etc." (GOFFMAN, 1991, p. 18, tradução da autor $\left.{ }^{5}\right)$. A pergunta se refere, então, às condições que permitem atribuir o status de realidade; o que está ligado "a um problema preciso, que diz respeito não ao que a máquina fotográfica captura, mas à própria máquina" (GOFFMAN, 1991, p. 10, tradução da 
autora ${ }^{6}$ ). Com isso Goffman quer dizer que a análise não é da situação propriamente dita, mas dos processos cognitivos de quem a percebe, avalia e nela age. Ele se coloca numa perspectiva situacional, mas focando "aquilo de que um indivíduo está consciente em determinado momento" (GOFFMAN, 1991, p. 16). Como coloca Velho (2008), para Goffman "era importante não só reconhecer a definição de situação como real, mas também verificar como se chegou a ela e, sobretudo, identificar os frames que possibilitam ou viabilizam diferentes definições" (p. 147), sendo que os frames podem ser observados em um indivíduo, ainda que sejam compartilhados e resultantes de um processo social.

Com a análise dos quadros, Goffman pretende articular a interação e a organização da experiência (NUNES, 1993). O frame, ou quadro, seria, então, categoria de mediação entre o indivíduo e a sociedade, que designa os "princípios de organização que estruturam os acontecimentos - pelo menos aqueles dotados de caráter social bem como nosso próprio engajamento subjetivo" (GOFFMAN, 1991, p. 19, tradução da autora ${ }^{7}$ ). São instrumentos de análise, através dos quais se pretende compreender a percepção, a construção e a ação dos indivíduos na realidade (VELHO, 2008).

Quadros primários são aqueles que não se referem a nenhum outro quadro interpretativo prévio, original; incluem, cada um deles, o conhecimento tido como certo sobre a realidade de determinada atividade. Estão presentes em qualquer situação, na identificação e distinção dos acontecimentos; e através deles é possível atribuir sentido aos diversos aspectos de determinada situação, sem os quais não teriam nenhum significado. Os quadros primários podem ser, segundo as diferentes atribuições de causalidade, naturais ou sociais. Os quadros naturais permitem identificar os acontecimentos puramente físicos, produzidos por determinantes "naturais", sem que a nenhuma consciência seja atribuída uma causa ou uma intenção. Já os quadros sociais permitem compreender outro tipo de acontecimento, em que estão em jogo a vontade ou os objetivos de uma "inteligência", uma consciência, "agentes vivos", sendo o primeiro deles o ser humano (GOFFMAN, 1991). Por exemplo, a "crença dos Azande no mau-olhado como causa de doença permite associar esta a um quadro primário social, enquanto nas sociedades ocidentais o mesmo fenômeno será, em geral, associado a um quadro natural" (NUNES, 1993, p. 36-37).

Os quadros primários, naturais ou sociais, em nossa sociedade, são compartilhados por todos os observadores em uma determinada situação, e não apenas por aqueles que participam da atividade. Uma olhada apenas já implica a mobilização de um ou vários quadros primários, e com isso as pessoas fazem suposições sobre a situação anterior e sobre o que acontecerá depois. No entanto, não se tem necessariamente consciência disso: 
Em suma, nunca deixamos de projetar nossos quadros de referência sobre aquilo que nos rodeia, mas não tomamos consciência disso, na medida em que os fatos venham a confirmá-los e o curso regular das atividades venham recobrir nossas conjecturas (GOFFMAN, 1991, p. 47, tradução da autora ${ }^{8}$ ).

Goffman (1991, p. 47-48) traz ainda um exemplo:

Uma mulher impecavelmente vestida que, depois de ter examinado atentamente o quadro de um espelho em uma loja, se recua para avaliar a qualidade de seu reflexo, provavelmente não chamaria a atenção das pessoas presentes. Ao contrário, se ela começa a arrumar seu chapéu, aqueles que a observam compreenderão então que ela na verdade só se interessava, desde o começo, por uma espécie de aparência própria, e que o objeto pregado na parede não era tanto um espelho à venda, mas simplesmente um espelho. E poderíamos dizer a mesma coisa da mesma mulher se ela avaliasse o espelho de um vestuário no lugar de se olhar nele.

Modalização e fabricação são transformações que se referem a uma realidade prévia, a um modelo "dotado de sentido em termos de quadro primário" (GOFFMAN, 1991, p. 94). No primeiro caso, procede-se por transposição, ponto por ponto, dos elementos presentes no quadro primário; e todos os participantes, ativos ou observadores, têm consciência de que se trata de uma transformação de elementos primários/literais. O exemplo típico seria o teatro, em que se representam situações da vida cotidiana; mas pode ser visto também no jogo, quando, por exemplo, brinca-se de lutar. Os acontecimentos que dão origem a essa transformação podem pertencer a todos os tipos de quadros, podem se referir a atividades técnicas (como a carpintaria), a rituais (como o casamento), etc. Nas fabricações, ao contrário, supõe-se que um ou vários participantes não saibam do "caráter 'fabricado' da situação em que se encontram" (NUNES, 1993, p. 37). "Trata-se se esforços deliberados, individuais ou coletivos, destinados a desorientar a atividade de um indivíduo ou de um conjunto de indivíduos, e que chegam a falsear suas convicções sobre o rumo das coisas" (GOFFMAN, 1991, p. 93). As fabricações podem ser benignas ou malignas. Uma festa-surpresa, por exemplo, não prejudica ninguém, enquanto que o 'conto do vigário' pressupõe a manipulação e a enganação, com danos para quem é submetido a ele. Os dois tipos de transformações podem ser analisados através da noção de quadro, sendo que a vida é sempre composta de múltiplos quadros, que se articulam uns com os outros.

Dois pontos merecem ser destacados. O primeiro deles diz respeito à questão da forma e do conteúdo. Se a análise dos quadros busca a 
“articulação entra a análise da interação, a experiência dos participantes e a dimensão cognitiva da participação" (NUNES, 1993, p. 39), percebe-se uma articulação entre a forma da interação e os conteúdos evocados em determinado momento, por cada participante, através dos quadros, compartilhados ou não. Por isso a necessidade de que sejam pontuados os "registros pertinentes", ou seja, o contexto em que a situação acontece. A mesma sequência de acontecimentos é interpretada de maneira diferente se tiver lugar no trabalho ou em uma festa, por exemplo. A subjetividade não emerge do tipo de interação em si, mas "da relação entre a interação e as condições estruturais - o quadro - que a organizam" (NUNES, 1993, p. 42).

O segundo ponto diz respeito às noções de indivíduo e sociedade. Goffman afirma várias vezes que não pretende atingir os problemas centrais da sociologia, como a organização ou a estrutura social. Ele se concentra na organização da experiência, naquilo "que um ator individual pode abrigar em seu espírito" (GOFFMAN, 1991, p. 22). Ele se volta para a "estrutura da experiência individual da vida social" ( $p$. 22 ). No entanto, o indivíduo parece ser apenas um meio de se atingir o outro pólo, pois não apenas ele aponta para uma homologia entre a estrutura microssocial e a macrossocial, como também dá prioridade à sociedade, e considera "os engajamentos de um indivíduo como secundários". Sobre Frame Analysis, diz: "este trabalho então trata apenas do que é secundário" (p. 22). Ao contrário de Simmel, Goffman ${ }^{9}$ não atribui aos indivíduos a origem dos conteúdos das interações e das próprias experiências individuais:

\begin{abstract}
A natureza humana universal não é uma coisa muito humana. Ao adquiri-la a pessoa torna-se uma espécie de construto que não é produzido pelas propensões psíquicas internas, mas pelas regras morais impressas nela a partir do exterior. Tais regras, quando seguidas, determinam a avaliação que a pessoa fará de si e dos seus colegasparticipantes dos encontros, a distribuição de seus sentimentos e os tipos de prática que empregará para manter um especificado e obrigatório tipo de equilíbrio ritual (GOFFMAN, apud TRAJANO FILHO, 2008, p. 170).
\end{abstract}

\title{
4 Uma comparação possível
}

Simmel e Goffman se colocam no centro do problema da relação indivíduo/sociedade. Ambos estão preocupados com categorias analíticas voltadas para a relação entre os dois pólos. Para Simmel, a matéria da sociação, na verdade, não são os indivíduos, mas sim a própria relação constituída na ação recíproca entre eles. I gualmente, Goffman (1991), reafirmando que a vida ordinária não é uma 
realidade soberana em relação às outras, coloca que "cada uma dessas realidades pode servir de original para uma simulação e nos conduzir a pensar que a realidade soberana é relação e não substância [...]" (p. 551-552). A relação é uma unidade analítica no centro da qual estão intrinsecamente ligados o indivíduo e a estrutura social. Uma relação que produz um duplo processo de socialização e subjetivação.

No entanto, o conceito de frame é, em certo sentido, mais abrangente do que o de sociação, pois, além da interação, diz respeito à dimensão cognitiva (e poderíamos até dizer afetiva) dos indivíduos. A análise dos quadros seria o plano em que "a 'natureza' da situação e o conteúdo da interação são articulados" (NUNES, 1993, p. 39). Simmel deixa os conteúdos da interação para outra disciplina (o que ele chama de sociologia geral), pois acredita que são originados por motivações individuais. Já Goffman os coloca no centro de um "senso comum" engendrado, compartilhado e controlado socialmente. Assim, Simmel procura pelas formas similares em contextos distintos (além dos exemplos já citados, podemos pensar no tipo do "estrangeiro", que pode se concretizar em um estrangeiro de fato como também na figura do pesquisador); enquanto na análise de Goffman o domínio em que acontece a interação é de fundamental importância. Ou seja, está em jogo o lugar da situação. Para o primeiro, a estrutura formal independe da situação em que acontece, e, para o segundo, o que interessa é exatamente a articulação da forma de interação com uma situação específica.

Mas não há apenas uma relação de complementaridade entre os dois. Podemos ver, através das categorias de mediação definidas, diferenças quanto às concepções mais amplas de indivíduo e sociedade. Na sociação, a forma é a mediação entre tipo e evento, entre o cristalizado e o situacional, "entre a construção tipológica e os processos concretos" dos acontecimentos (TAVARES, 2001, p. 80); indicando a produção da sociedade. A sociedade não se reduz aos indivíduos, mas, no limite, se reduz às interações. Nos frames, não encontramos o mesmo caráter produtor das relações sociais. A forma se associa necessariamente aos conteúdos situacionais, mas fazendo do microssocial mais uma reprodução do macrossocial do que propriamente uma construção, já que, levando a idéia ao extremo, além das formas, os conteúdos também são construídos nos indivíduos, e não por eles.

Mesmo que Simmel também procure ver a permanência das formas sociais e que Goffman, por outro lado, preste também a atenção ao que escapa à ordem, a visão da relação indivíduo/sociedade em Goffman diz mais da norma e da reprodução - como os "múltiplos mundos" reproduzem, de certa forma, a vida cotidiana. Assim, mesmo que em certo sentido o conceito de frame seja mais abrangente do que o de sociação, são visões - ou pontos de vista - 
diferentes da relação sujeito-sociedade que sustentam cada um dos conceitos. Talvez a articulação das duas categorias - da que se volta mais para a reprodução com aquela que tende para o lado da produção-, ao permitir olhar para o fenômeno a partir de ângulos que se diferem, mas também se complementam, possa contribuir para uma melhor compreensão da complexa relação sujeito-sociedade.

\section{Referências}

COHN, G. As diferenças finas: Simmel e Luhmann. Revista Brasileira de Ciências Sociais (online), v. 13, n. 38, São Paulo, out. $1998 . \quad$ Disponível em: <http://www.scielo.br/scielo.php?script=sci_arttext\&pid=S010269091998000300003\&lng=pt\&nrm=iso>. Acesso em: 15 ago. 2010. FERREIRA, J. Da vida ao tempo: Simmel e a construção da subjetividade no mundo moderno. Revista Brasileira de Ciências Sociais (online), v. 15, n. 44, p. 103-117, out. 2000. Disponível em: $<$ http://www.scielo.br/scielo.php?script=sci_arttext\&pid=S0102$69092000000300006 \&$ lng =pt\&nrm=iso >. Acesso em: 15 jun. 2009. GOFFMAN, E. Les cadres de l'expérience. Paris: Les éditions de minuit, 1991.

GOFFMAN, E. The interaction order: American Sociological Association, 1982 Presidential Address. American Sociological Review, v. 48, n. 1, p. 1-17, fev. 1983. Disponível em: <http://www.jstor.org/stable/2095141>. Acesso em: 10 ago. 2010. JOSEPH, I. Erving Goffman e a microssociologia. Rio de Janeiro: Editora FGV, 2000.

MALUFE, R. A retórica da ciência: uma leitura de Goffman. São Paulo: Educ, 1992.

MORAES FILHO, E. Introdução. In: SIMMEL, G. (Org.). Simmel: sociologia. Coleção Grandes Cientistas. São Paulo: Editora Ática, 1983, p. 7-44.

NOGUEIRA, P. H. de Q. I dentidade juvenil e identidade docente: processos de escolarização no terceiro ciclo da escola pública. 2006. 378f. Tese (Doutorado em Educação) - Programa de Pós-Graduação em Educação, Universidade Federal de Minas Gerais, Belo Horizonte, 2006.

NUNES, J. A. Erving Goffman, a análise de quadros e a Sociologia da vida cotidiana. Revista Crítica de Ciências Sociais, Coimbra, n. 37, p. 33-49, jun. 1993.

SIMMEL, G. As grandes cidades e a vida do espírito. Mana, Rio de Janeiro, v. 11, n. 2. p. 577-591, out. 2005.

SIMMEL, G. Simmel: Sociologia. Coleção Grandes Cientistas Sociais. São Paulo: Editora Ática, 1983. 
SIMMEL, G. The Sociology of conflict I. The American Journal of Sociology, Chicago, v. 9, n. 4, p. 490-525, jan. 1904. Disponível em: <http://www.jstor.org/stable/2762175>. Acesso em: 15 ago. 2010.

SIMMEL, G. Le problème de la Sociologie. Revue de Métaphysique et de Morale, t. II, p. 497-504, 1894. Disponível em: $<$ http://www.ac-nancymetz.fr/enseign/philo/textesph/Simmel_Probleme_de_la_ sociologie. pdf $>$. Acesso em: 10 ago. $20 \overline{10}$.

STECHER, H. Georg Simmel: dinheiro, a solidez do efêmero. Caderno CRH, Salvador, v. 8, n. 22, p. 85-91, jan./jun. 1995.

TAVARES, F. R. G. Schutz e Simmel: sobre os dilemas da condição social do "estrangeiro". Comum, Rio de Janeiro, v. 6, n. 17, p. 7890, jul./dez. 2001.

TRAJANO FILHO, W. Goffman em África e entre os músicos: reflexões sobre a influência de sua obra. Revista Brasileira de Ciências Sociais (online), v. 23, n. 68, p. 167-176, out. 2008. Disponível em: <http://www.scielo.br/scielo.php?script=sci_arttext\&pid=S0102$69092008000300015 \&$ lng =pt\&nrm=iso >. Acesso em: 15 jun. 2009. VANDENBERGHE, F. Simmel and Weber as ideal-typical founders of Sociology. Philosophy \& Social Criticism, Londres, v. 25, n. 4, p. 57-80, 1999. Disponível em: <http://psc.sagepub.com/content/25/4/57>. Acesso em: 19 ago. 2010.

VELHO, G. Goffman, mal-entendidos e riscos interacionais. Revista Brasileira de Ciências Sociais (online), v. 23, n. 68, p. 145-148, out. $2008 . \quad$ Disponível em : <http://www.scielo.br/scielo.php?script=sci_arttext\&pid=S0102$69092008000300012 \&$ lng =pt\&nrm=iso >. Acesso em: 15 jun. 2009.

\section{Endereço para correspondência}

I sabelle de Paiva Sanchis

Programa de Pós-Graduação em Psicologia, Faculdade de Filosofia e Ciências Humanas - FAFICH, Universidade Federal de Minas Gerais - UFMG, Av. Antônio Carlos, 6627. Caixa Postal 253, CEP 31270-901, Belo Horizonte- MG, Brasil.

Endereço eletrônico: isabellesanchis@yahoo.com.br

Recebido em: 22/03/2010

Reformulado em: 02/09/2010

Aceito para publicação em: 08/09/2010

Acompanhamento do processo editorial: Ariane Patricia Ewald

\section{Notas}


* Doutoranda em Psicologia Social pelo Programa de Pós-Graduação em Psicologia da UFMG. Psicóloga e Mestre em Psicologia pela Universidade Federal de Minas Gerais - UFMG.

1“[...] ne considere que la forme spaciale du corps, qui, cependant, n'existe pás pour elle seule, mais toujours dans et avec une matière, laquelle est objet d'autres sciences".

${ }^{2}$ SIMMEL, G. The conflict in modern age and other essays. Nova York, Teachers College Press, Columbia University, 1968.

${ }^{3}$ SUMNER, W.G.; KELLER, A.G. The science of society. New Haven, 1927.

4“My concern over the years has been to promote acceptance of this face-to-face domain as an analytically viable one - a domain which might be titled, for want of any happy name, the interaction order - a domain whose preferred method of study is microanalysis".

5“[...] une chose qui dans certaines circonstances peut se présenter comme la réalité peut en fait être une plaisanterie, un rêve, un accident, un malentendu, une illusion, une représentation théatrâle, etc".

${ }^{6}$ “[...] à un problème précis qui tient non pas à ce que l'appareil prend en photo mais à l'appareil lui-même".

7 “....] principes d'organisation qui structurent les événements - du moins ceux qui ont un caractère social - et notre propre engagement subjectif".

8“En somme, nous ne cessons de projeter nos cadres de référence sur ce qui nous entoure, mais nous ne nous en apercevons pas, dans la mesure ou les faits viennent les confirmer et les cours régulier des activités recouvrir nos conjectures".

${ }^{9}$ GOFFMAN, E. Interaction ritual: essays on face-to-face behavior. Nova York, Anchor Books, 1967. 